\title{
Noninfectious Bud Failure in 'Carmel' Almond: I. Pattern of Development in Vegetative Progeny Trees
}

\author{
Dale E. Kester, Kenneth A. Shackel, and Warren C. Micke \\ Department of Pomology, University of California, Davis, CA 95616 \\ Mario Viveros \\ University of California Cooperative Extension, Bakersfield, CA 93307 \\ Thomas M. Gradziel \\ Department of Pomology, University of California, Davis, CA 95616
}

Additional Index words. Prunus dulcis, Prunus amygdalus, somaclonal variation, genetic disorders, epigenetic models.

\begin{abstract}
The spatial and temporal pattern of noninfectious bud failure $(\mathrm{BF})$ expression $\left(\mathrm{BF}_{\text {exp }}\right)$ was studied during seven growing seasons in a population of 'Carmel' almond trees originating from twelve commercial propagation sources. All progeny trees were grown in a single experimental site with high prevailing summer temperatures. $\mathrm{BF}_{\mathrm{exp}}$ increased continuously but irregularly in each nursery population as measured as the proportion of trees showing $\mathrm{BF}$ and as an average $\mathrm{BF}_{\mathrm{exp}}$ rating. Populations from the 12 nurseries represented increasing clonal generations from the original seedling tree and showed increasing levels of $\mathrm{BF}$, as well as a decreasing shape value and increasing scale value derived by a failure statistics model. Models for development, distribution and hazard functions were defined for each of the 12 sources studied. Only sources from the original tree and source A demonstrated potential for commercial use. A significant correlation was found between average yearly increase in $\mathrm{BF}_{\exp }$ and the average daytime temperature for the previous June. The June period coincides with a specific stage in the seasonal growth cycle when vegetative buds mature.
\end{abstract}

Noninfectious bud failure (BF) is a genetic disorder of almond [Prunus dulcis (Mill.) D.A.Webb.] (IPM Education and Publication, 2002; Kester, 1974; Kester and Gradziel, 1996). The disorder is identified in individual orchard trees of certain cultivars by failure of vegetative buds to grow in the spring (BF), die-back of terminal shoots (dieback), vigorous and erratic growth from surviving buds (witches-broom) and characteristic bark deformations (roughbark). Flowering and fruiting are not directly affected but bloom can be delayed and flowering density reduced, and so crop production can be reduced.

There is no evidence of a pathological cause (DiTerlizzi et al., 1998; Wilson and Schein, 1956; Fenton et al., 1988a) although some viruses mimic the symptoms of BF (Kester. 1974; Wilson and Schein, 1956). BF is equally inherited in almond $x$ almond reciprocal crosses and is directly proportional to the BF severity in the parents (Kester, 1968a, 1968b; Kester and Jones, 1970). Individual seedlings inherit different levels of the potential for $\mathrm{BF}\left(\mathrm{BF}_{\mathrm{pot}}\right)$ which is manifested in the number of cycles of future growth required for symptoms to be expressed. Individual seedlings pass through a period of conversion in which the $\mathrm{BF}_{\mathrm{pot}}$ changes to expression $\left(\mathrm{BF}_{\text {exp }}\right)$. The pattern is retained during vegetative propagation and is continued during further vegetative generations. $B F$ is also inherited in almond $x$ peach $F_{1}, F_{2}$ and backcross progeny where $\mathrm{BF}_{\text {exp }}$ segregation indicates that a major gene for $\mathrm{BF}$ occurs in almond which is absent in peach (Kester 1978; Kester and Gradziel, 2002).

$\mathrm{BF}_{\text {exp }}$ first appeared sporadically in 'Nonpareil' and 'Peerless' in the early years of the industry and later at a devastating rate in 'Jordanolo' and 'Harpareil', both products of a USDA-UC breeding program (Woods, 1938). Later, $\mathrm{BF}_{\text {exp }}$ has appeared in high numbers in patented cultivars such as 'Merced', 'Price',

Received for publication17 Dec. 2002. Accepted for publication 1 Aug. 2003. Partial financial support for this project was supplied by the Almond Board of California, Modesto, Calif., and IAB, Sacramento, Calif. Thanks are also due to Paramount Farms, Bakersfield, Calif., for providing the orchard space and management of test plot. and 'Carmel', which were all chance seedlings of 'Nonpareil' selected by nurseries (Kester, 1993). BF became a serious problem as the almond industry spread into the hot summer regions of California. 'Carmel' was introduced in 1965 and was widely planted in commercial orchards since 1971, becoming the second most important variety after 'Nonpareil' with a current planting of $\approx 40,000$ ha (Almond Board of California, 2002). By 1990, $\mathrm{BF}_{\text {exp }}$ in 'Carmel' had become so severe that the future of the cultivar was threatened.

Historically, nursery budwood sources of almond have been from carefully selected healthy orchard trees. Budsticks are collected in May for June budding to produce nursery trees in one year. At digging, nursery trees are sorted by caliper (trunk diameter), which effectively obscures the origin of trees when sold. An alternate method of budwood selection was introduced in 1969 which consists of pedigreeing all trees to a single selected tree that had been indexed as virus-free and from which clones of Registered and Certified nursery trees are produced (CDFA Deciduous Fruit and Nut Program Regulations, 1984).

The increasing proportion of $\mathrm{BF}_{\text {exp }}$ in orchard trees is a dynamic process depending on the age of the tree and the severity of symptoms when first expressed. Variability in $\mathrm{BF}_{\mathrm{pot}}$ and associated $\mathrm{BF}_{\text {exp }}$ differ depending on cultivar (Kester, 1994) and type of propagation source within clones (Kester and Asay, 1978a). Patterns of $\mathrm{BF}_{\text {exp }}$ are also related to the environment in which the almond plants are grown. Kester and Asay (1978b) showed that the rate at which $\mathrm{BF}_{\text {exp }}$ develops within orchards depends on the temperature to which the trees are subjected during the previous summer. The effect of temperature on BF severity was confirmed in greenhouse (Kester et al., 1976) and growth chamber (Hellali and Kester, 1979) tests.

Fenton et al. (1988a) adapted a series of mathematical models to characterize increasing incidence and distribution of trees with $\mathrm{BF}_{\text {exp }}$ within orchard populations of 'Nonpareil' and 'Carmel'. These models (Lawless, 1982; Lee, 1980) were based on Weibull 
distributions (Weibull, 1951), which characterize the pattern of failure for specific events in a population of dynamically changing events. The model has three aspects. One, cumulative probability, measures the change in numbers of trees with $\mathrm{BF}_{\text {exp }}$ with time and temperature. Years are an independent variable while scale and shape are specific model parameters. (Fenton et al., 1988b). The rate of increase in trees affected with $\mathrm{BF}_{\text {exp }}$ was directly proportional to day-degrees (DD) $>28^{\circ} \mathrm{C}$. Two other related aspects were a distribution function and a hazard function.

The research for this paper was initiated when $\mathrm{BF}_{\text {exp }}$ became so severe in orchards of 'Carmel' that its future as a commercial cultivar was threatened. This paper focuses on the variability in $\mathrm{BF}_{\text {exp }}$ among trees within a 'Carmel' orchard composed of the vegetative progeny of the individual trees used as propagation sources by major California nurseries. The population essentially reproduced the range of commercial progeny for the entire 'Carmel' cultivar. The goals of this research are a) to define the temporal and spatial patterns of $\mathrm{BF}_{\text {exp }}$ in populations of 'Carmel' orchard trees of differing nursery origin, $b$ ) to characterize subpopulations within 'Carmel' relative to $\mathrm{BF}_{\text {pot }}$ and to predict their long term trends in $\mathrm{BF}_{\mathrm{exp}}$ based on the Fenton models, and c) to correlate the increase in $\mathrm{BF}_{\text {exp }}$ over time to seasonal temperature patterns. To carry out these three objectives, an artificial population was created that represented the entire 'Carmel' commercial planting.

\section{Materials and Methods}

Eleven commercial nurseries provided source and progeny trees representative of those used for commercial propagation of 'Carmel' almond in 1990. No tree selected as a source showed BF ${ }_{\text {exp }}$ at the time of budwood collection. The number of individual source trees varied from 1 to 25 trees per nursery. Ten standard budsticks were collected from each of four quadrant branches of the source tree (south, west, north, and east). In the nursery row, identity of each budstick was maintained and propagators were instructed to propagate each bud of a budstick in the same sequence as its base to apex order. All trees were single budded on 'Nemaguard' rootstock.

After the budded seedling had been cut back and the 'Carmel' shoot emerged, each nursery tree was labeled with a unique number, which remained with the nursery tree during the digging operation and to the final planting in the test orchard. Planting was carried out in random groups of 10 trees each. Planting was made in a commercial orchard located in northwestern Kern County in California, an area known for high expression of BF symptoms. Nursery trees were planted in January 1991, pruned to a single stem of $\approx 200 \mathrm{~cm}$ in height. After the trees were planted, the orchard was mapped with the identity of each tree located by row and tree position, verified twice and the labels removed. Tree locations were entered into a computer file and identity was maintained by code and remained anonymous throughout the entire experiment.

'Nonpareil' trees were planted in alternate rows with 'Carmel' test trees to provide cross-pollination. The entire block of trees was evaluated each March when a team of three investigators rated the $\mathrm{BF}_{\text {exp }}$ of individual trees. Visual ratings were assigned as follows: $0=$ none; $1=$ slight, $1 \%$ to $10 \%$ of the shoots affected, usually located in the top of the tree; $2=$ moderate, $11 \%$ to $25 \%$ of tree (or shoots) affected, often in upper part of tree; $3=$ severe, $26 \%$ to $50 \%$ of the tree (or shoots) affected; and $4=$ very severe, $\geq 50 \%$ of the tree (or shoots) affected.

$\mathrm{BF}_{\text {exp }}$ populations were quantified as the percent of trees expressing $\mathrm{BF}$ and as the average $\mathrm{BF}$ severity. All statistical analyses were performed with SAS (SAS Institute, 1998), using PROC NLIN for the estimation of scale and shape parameters (Fenton et al., 1988b) from the percentage of BF trees in each sample of trees. Hourly average air temperature data were obtained from a nearby CIMIS station (California Irrigation Management and Information System \#544, Blackwells Corner, Kern Co., Calif.) and summarized as monthly means of either day-degrees, 24-h means, or as daylight period (0600 to $1800 \mathrm{HR}$ ) means. The BF symptoms recorded in the spring of each year were correlated to the previous year's temperature data, and are referred to by the year of symptom expression.

\section{Results}

QUALITATIVE PATTERN OF BF DEVELOPMENT IN INDIVIDUAL TREES. Shoot growth was vigorous during the first growing season, continuing through the summer in a series of terminal and lateral flushes resulting in bushy trees that were $\geq 2 \mathrm{~m}$ in height. Trees were pruned in the dormant season to retain three to four main branches for primary scaffolds, as is the standard commercial practice for the area.

When the orchard was examined in March 1992, a range of $\mathrm{BF}_{\text {exp }}$ symptoms was observed on the primary branches which varied among individual trees in the number and distribution of buds that had failed (bud failure). Bud failure on individual long shoots showed a more or less continuous gradient of failed buds from tip to base with differences among shoots determined by how far down the shoot, failure occurred. The vertical distribution of visual BF within individual branches of first year trees also provided a quantitative base of BF severity rating. $0=$ none; 1 (slight) $=5 \%$ to $10 \%$ of the apical buds affected; 2 (moderate $)=$ $11 \%$ to $25 \%$ of apical buds affected; 3 (severe) $=$ about $26 \%$ to $50 \%$ of apical buds failed; 4 (very severe) $=51 \%$ to $100 \%$ of buds failed. Late season flushes of shoot growth were almost entirely free of BF. Areas of rough bark were sometimes associated with more severe BF.

Shoot growth of initially normal trees during the second year was similar to first year's growth, though with less total vertical extension of individual shoots. A larger canopy volume was produced due to the greater number of current season shoots. On BF-affected trees, vigorous new growth developed from the surviving buds. Trees were pruned during the second dormant season to retain seven to nine secondary scaffolds that were not cut back except for removal of some excess branching.

The growth pattern during the third season was similar to earlier patterns but involved less extension growth overall, increased numbers of lateral and terminal shoots and increased volume and height of the canopy. Affected shoots from the previous year showed BF scars with extensive new growth from surviving buds. Spurs began to appear as short fruiting laterals on normal shoots that produced flower buds. Spur production from vigorous shoots on former BF branches was inhibited. Pruning at the end of the year was primarily to thin out excess branching.

Visual symptom ratings in March 1994 reflected a composite of three categories: proportions of failed buds on shoots, BF location within the tree and proportion of the canopy involved. Flowering occurred and some crop was produced laterally on both shoots and spurs. Increasing proportions of spurs relative to the longer vegetative shoots occurred in each succeeding year, though to a lesser extent, on shoots with BF.

QUANTITATIVE PATTERN OF DEVELOPMENT. Quantitative evaluations used the number of affected nodes to provide severity ratings 


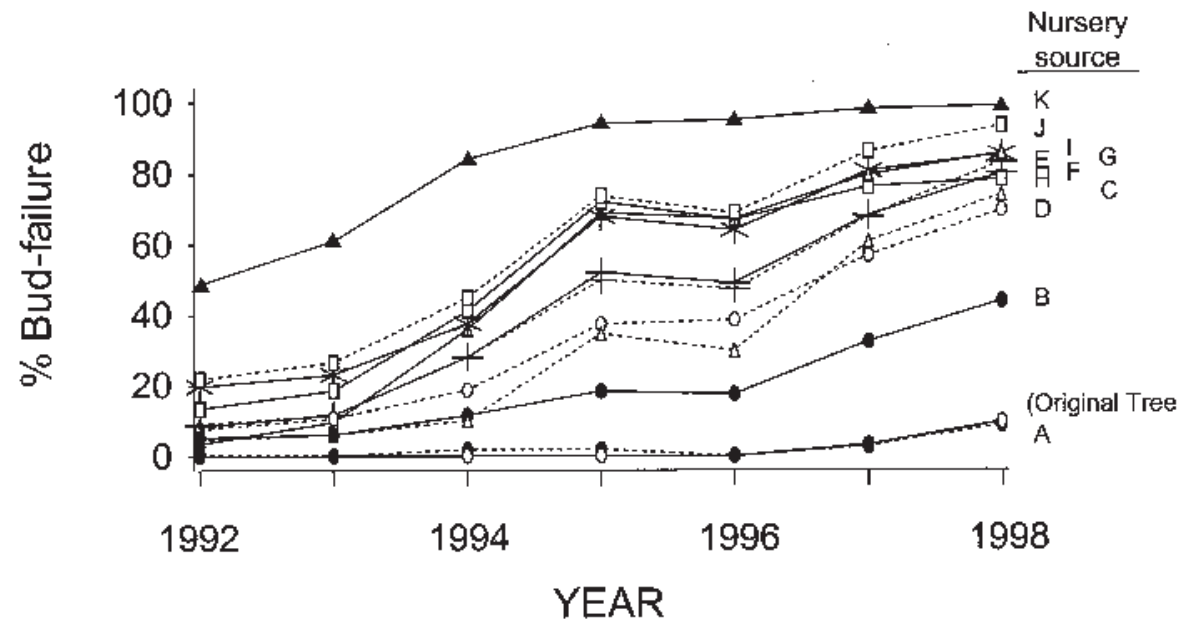

individual trees ranged from 0 to 4 , showing that trees were present ranging from none to very severe BF (Fig. 2). In 1993, the severely affected trees (rated as 4 in 1992) continued to rate just under 4. Others rating less in 1992 (i.e., 1 to 3 ) rated higher the second year indicating an increasing rate of conversion from low to high $\mathrm{BF}$ during consecutive growth periods. Increased ratings reflect more overall buds failing and/or an increase in the size of the affected canopy. The rating in any 1 year thus reflects the cumulative effect of several preceding years. This also means that the trees with symptoms at the end of the first year reflect internal increases in $\mathrm{BF}_{\text {pot }}$ present during propagation. These trees always showed severe BF symptoms in future generations.

Fig.1. Percentage of bud failure (BF) trees $(\mathrm{BF}>0)$ originating from 12 different nursery sources, based on visual ratings of symptoms over seven seasons of observations. A-K = different nursery sources.

Trees that show symptoms of a lesser $\mathrm{BF}_{\exp }$ intensity at the end of the first year increased in succeeding years as they reached orchard maturity and came into bearing. Similarly, certain sources

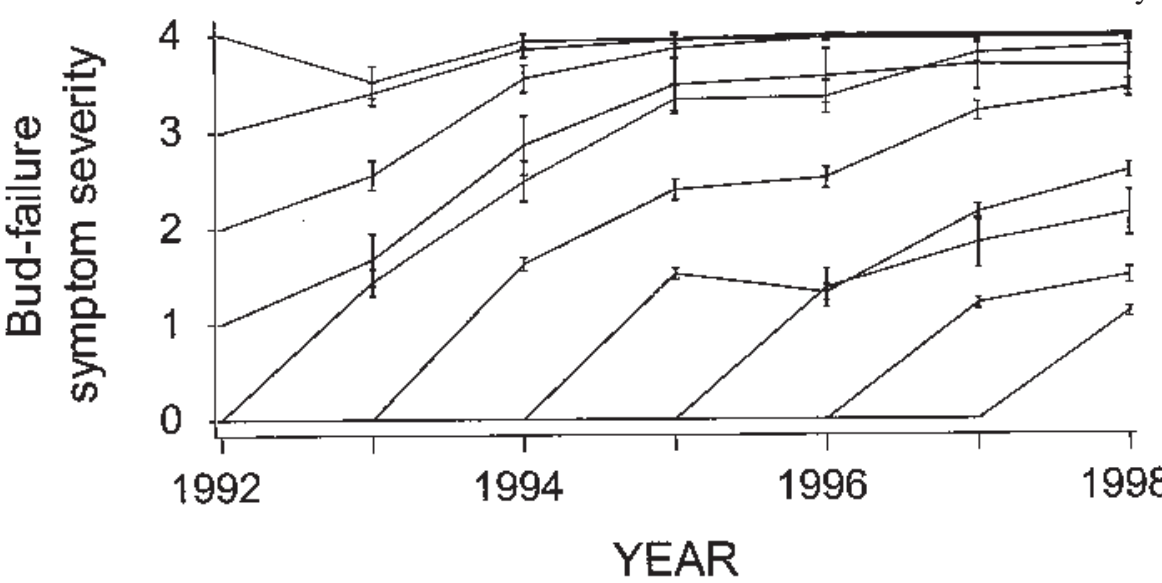
did not show symptoms during the early years in the orchard but did express BF later (Figs. 1 and 2).

The years required to reach the high levels of BF severity were directly related to tree severity at first $\mathrm{BF}$ appearance. Trees initiating $\mathrm{BF}_{\text {exp }}$ in subsequent years followed the same pattern, [i.e., BF ratings increased each year up to the time of tree maturity at about the fifth year (Fig. $2)$ ]. The greater the age of initiation, the less severely trees were rated since affected branches were located higher in the tree and represented a smaller proportion of total tree canopy. Similarly, the earlier the age of initiation, the greater the ultimate rating because greater proportions of the canopy were affected.

Fig. 2. Pattern of bud failure (BF) development relative to the year of first expression. Individual plots show averaged BF ratings for all sources initiating symptom development on the same year. Vertical lines represent $\pm 2 \mathrm{SE}$.

on the previous year's growth as observed the following spring. $\mathrm{BF}_{\text {exp }}$ developed during the summer season and the rating for $\mathrm{BF}$ was first made in March 1992 (Fig. 1). At this time, the rating of

The overall percentage of $\mathrm{BF}_{\text {exp }}$ trees increased more or less continuously beginning with the second year. Eventually all sources produced some vegetative progeny trees with BF, although the timing, severity and quantity differed among sources. Most sources exhibited parallel patterns of BF development over the 8 years of the study.

Table 1. Population parameters of bud failure $\left(\mathrm{BF}_{\mathrm{exp}}\right)$ for 'Carmel' based on the Fenton et al (1988a) BF expression model.

\begin{tabular}{|c|c|c|c|c|c|}
\hline $\begin{array}{l}\text { Nursery } \\
\text { source }\end{array}$ & Final BF \% & $\begin{array}{c}\text { Clonal } \\
\text { generation }\end{array}$ & $\begin{array}{c}\text { No. } \\
\text { of trees }\end{array}$ & Shapey & Scalex \\
\hline Orig. tree & 1.8 & 0 & 31 & 8.14 & 10.8 \\
\hline A & 2.2 & $n d^{w}$ & 217 & 7.76 & 10.5 \\
\hline B & 19.3- & 3 & 234 & 2.65 & 15.7 \\
\hline $\mathrm{C}$ & 31.5 & 3 & 297 & 1.95 & 10.3 \\
\hline D & 34.5 & nd & 235 & 1.94 & 22.3 \\
\hline $\mathrm{E}$ & 42.5 & 3 & 78 & 1.85 & 15.1 \\
\hline $\mathrm{F}$ & 42.5 & 3 & 407 & 1.82 & 18.1 \\
\hline G & 50.1 & 3 & 261 & 1.75 & 18.1 \\
\hline $\mathrm{H}$ & 52.4 & nd & 97 & 1.44 & 27.2 \\
\hline I & 54.0 & d & 234 & 1.40 & 22.3 \\
\hline J & 59.4 & 5 & 320 & 1.41 & 22.7 \\
\hline K & 83.0 & 5 & 291 & 1.00 & 58.8 \\
\hline
\end{tabular}

${ }^{2}$ Clonal generation from original seedling tree.

y Parameter that measures the average deviation from an exponentially distributed curve.

Parameter that measures the relative rate of increase in $\mathrm{BF}_{\text {exp }}$ per year.

${ }^{w}$ nd $=$ not determined. 

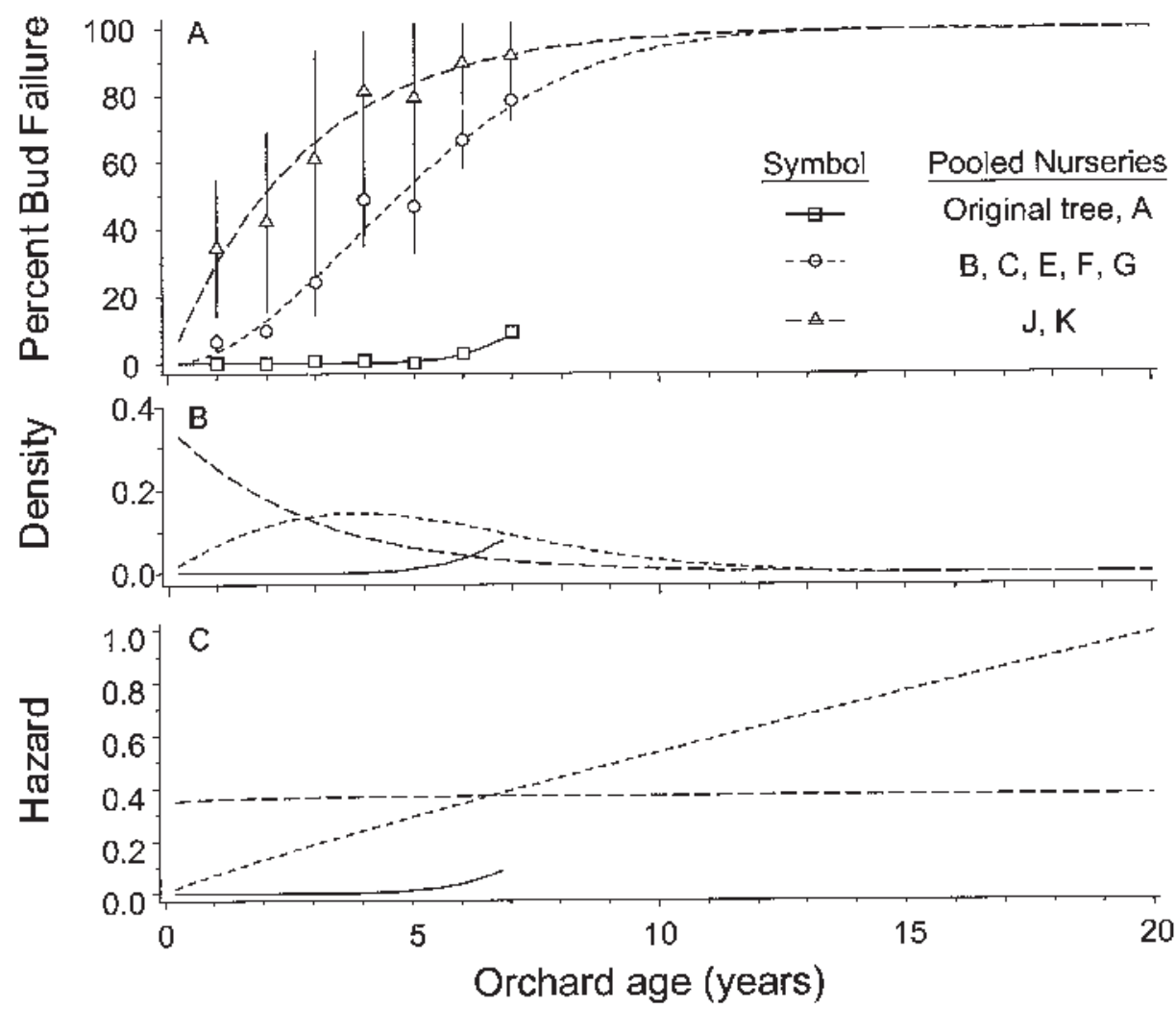

Fig. 3. (A) Measured (symbols) and predicted (lines) for percent bud failure (BF) among nursery sources that were pooled based in the number of clonal generations from the original 'Carmel' seedling. Vertical lines represent \pm 1 SD for the pooled nursery mean. Lines through the data points are nonlinear regression equations from the Fenton model for BF development (Fenton et al., 1988a). Also shown are the density $(\mathbf{B})$ and hazard $(\mathbf{C})$ curves derived from the model for the three pooled populations.

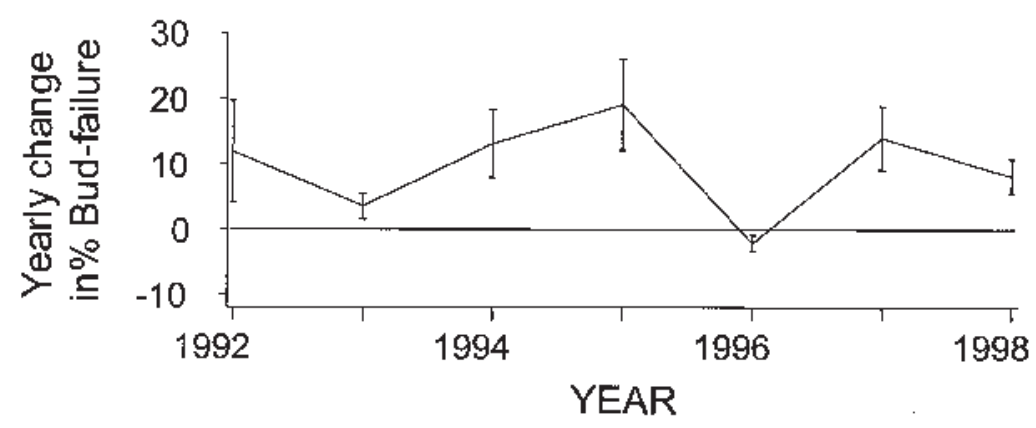

Fig. 4. Average yearly change in percent bud failure (BF) for the 12 nursery sources shown in Fig. 1. Vertical lines represent \pm 2 SE for the yearly averages.

Characterization of 'CARmel' Populations Using the FenTON BF MODEL. In this study, model data were used to characterize each 'Carmel' source population and to predict the future development of $\mathrm{BF}_{\text {exp }}$. This was done using the BF Development Model (Fenton et al., 1988b) which characterized the increasing pattern of $\mathrm{BF}_{\text {exp }}$ over time with an overall scale value of 0.17 (average annual increase in percent BF over the 8 years of the experiment) and the overall shape value 1.34 , (which measured the average deviation from an exponentially distributed curve).

The entire population (original tree through nursery source K) was composed of 12 populations, each representing a separate nursery source. Each nursery source was characterized by the final percent BF, a shape value and a scale value (Table 1). In Table 1, the nursery sources are ordered by their increasing clonal genera- tions from the original 'Carmel' seedling tree. Results show an increase in the final percent $\mathrm{BF}$, an increasing scale value and a decreasing shape value relative to the original seedling plant (Table 1). Results are shown graphically in Fig. 3A using the $\mathrm{BF}$ development model where the original seedling source, nursery source A, (generation unsure), sources B,C,E,F, G (all of the 3rd clonal generation) and nursery sources J, K (both 5th clonal generation) are compared. The original seedling source and source A showed low $\mathrm{BF}_{\text {pot }}$ in which the progeny did not begin to develop $\mathrm{BF}_{\text {exp }}$ until after five to six yearly cycles. At this age of development, the affected area of the tree is not likely to be significant economically). The model for the composite 3 rd generation represents an intermediate $\mathrm{BF}_{\text {pot }}$ in which $\mathrm{BF}_{\text {exp }}$ appeared in only a few of the progeny trees in the first year and with an increasing number in the subsequent 6 years with commercial plantings likely to be discarded by this time. The 5 th generation (nursery sources $\mathrm{J}$ and $\mathrm{K}$ ) represented high $\mathrm{BF}_{\mathrm{pot}}$ in which $\mathrm{BF}_{\text {exp }}$ occurred in a high percentage of progeny after the first year and increased to higher levels in subsequent years. These trees would not be economically viable and so would be replaced within the first years of growth.

The model for the 3rd and 5th clonal generations has been projected to predict essentially $100 \% \mathrm{BF}_{\exp }$ at $\approx 10$ years. The projection for the original seedling plant as well as source $\mathrm{A}$ was not attempted because the delay in initial appearance of BF makes its estimates unreliable.

Figure 3B (BF density function) presents the second kind of distribution that can be deduced from the $\mathrm{BF}$ model. The common denominator is the number of years required for expression. Curves from the combined sources make a normal distribution curve. The low $\mathrm{BF}_{\text {pot }}$ sources represent the beginning of a normal distribution curve. The intermediate $\mathrm{BF}_{\text {pot }}$ sources project essentially the center of a normally distributed curve. The high $\mathrm{BF}_{\text {pot }}$ sources $(\mathrm{J}, \mathrm{K})$ represent the descending slope at the upper end of the curve. All three distributions combined represent the distribution of $\mathrm{BF}_{\mathrm{exp}}$ in the entire 'Carmel' cultivar.

Figure $3 \mathrm{C}$ (hazard function) presents a third type of distribution that predicts the probability of the remaining nonexpressing $\left(\mathrm{BF}_{\mathrm{pot}}\right)$ trees of the population to produce $\mathrm{BF}_{\text {exp }}$ in the future. Here the original tree and source A have a very low hazard and represents the type of source for which budwood programs would be searching. Intermediate sources (B, C, E, F, and G) show an increasing probability of developing $\mathrm{BF}_{\text {exp }}$ in their vegetative progeny with time and would eventually be discarded.. Sources $\mathrm{J}$ and $\mathrm{K}$ show a constant hazard of producing severely affected progeny and should be quickly discarded.

BF Seasonal temperature pattern. A comparison of the change in percent $\mathrm{BF}$ across all source populations for different years showed that differences in BF increase varied by years but were consistent among sources (Fig. 4). Correlating the percent annual change in numbers of new BF trees against different temperature parameters showed that the highest correlation between 


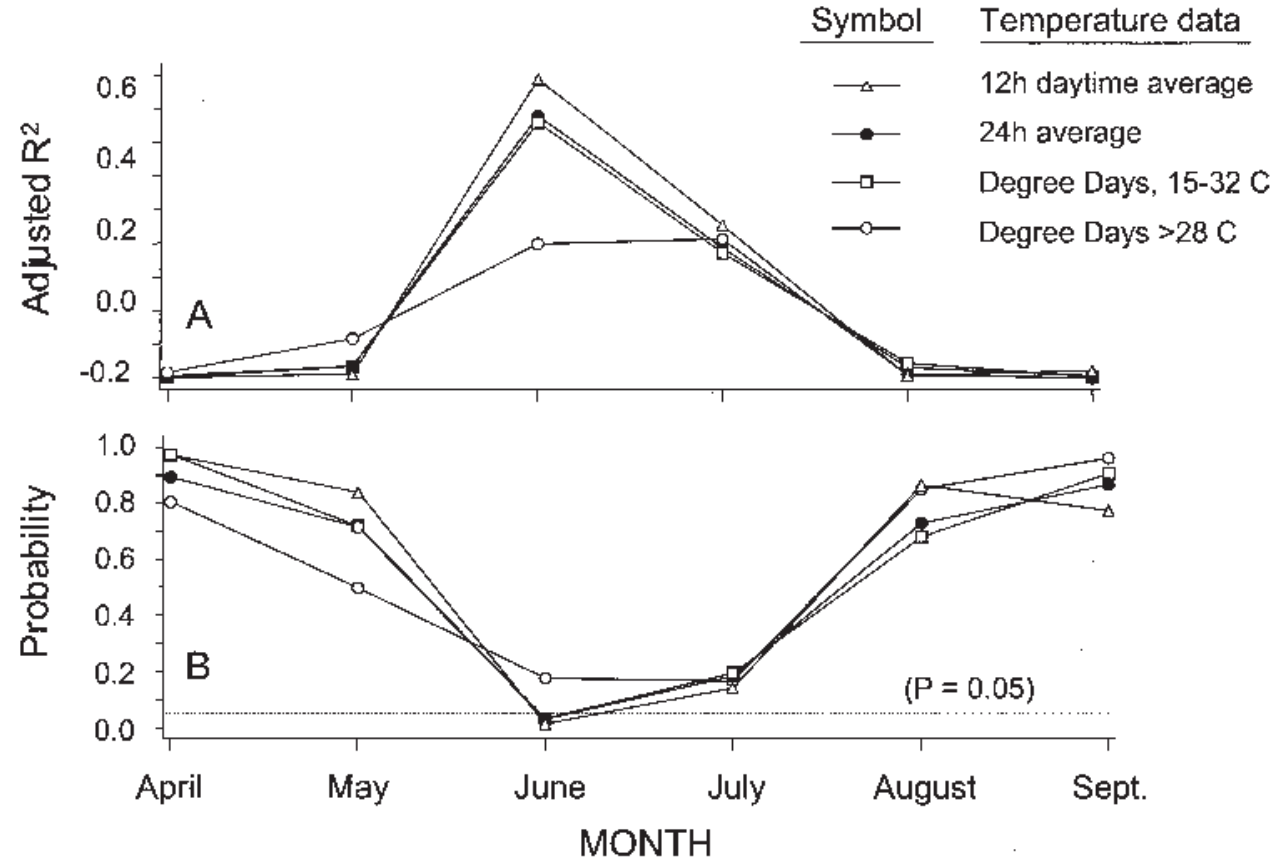

Fig. 5. Adjusted correlation coefficients (A) and associated probabilities (B) for the relation of the yearly change in percent bud failure (BF) (as in Fig. 4) to the temperature regime experienced during different months of the previous year, characterized by four alternative measures of temperature regime.

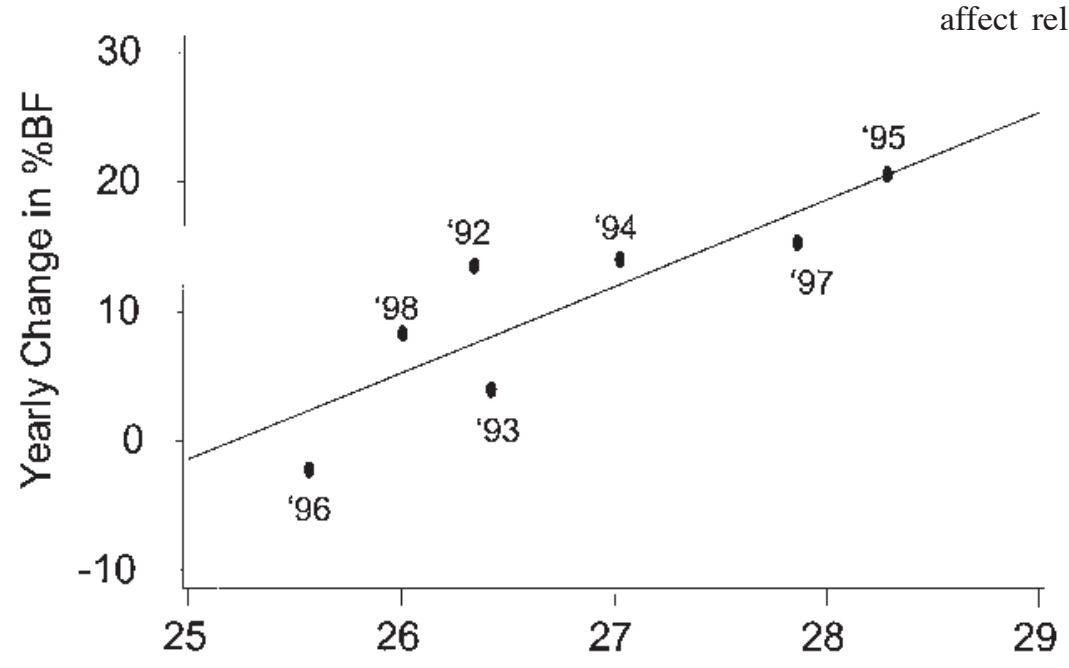

Average Day Temperature, Previous June (C) over 8 years. The test population was created to represent the entire 'Carmel' cultivar as produced by commercial nurseries in California in 1990. All source trees were asymptomatic for $\mathrm{BF}_{\text {exp. }}$. Some progeny of all source trees of 'Carmel' produced $\mathrm{BF}_{\text {exp }}$ by the end of the experiment. Patterns could be visually characterized either as percent trees affected (percent $\mathrm{BF}$ ) or average $\mathrm{BF}$ rating (avBF). The rating scale for severity was based on proportion of the canopy affected. Results show that even at the beginning of the test, all 'Carmel' trees had demonstratable $\mathrm{BF}_{\text {pot }}$

Population variability. $\mathrm{BF}_{\text {exp }}$ appeared in some trees at the end of the first year with more in subsequent generations. A continuous distribution of buds with $\mathrm{BF}_{\text {exp }}$ appeared, both in relation to age (time) and location within the tree (spatial). The phenotypic expression of $\mathrm{BF}$ within and among trees showed an interaction between the time (age) at which $\mathrm{BF}_{\text {exp }}$ appeared and the stage of canopy development. Earlier BF appearance in a tree resulted in more of the canopy's being ultimately affected. Rating was a function of age, since a later appearance of $\mathrm{BF}_{\exp }$ would affect relatively less of the canopy. The relationship between $\mathrm{BF}_{\text {exp }}$ distribution and tree structure also indicates a permanent change occurring within the buds. Consequently, once BF occurs in a branch, that part of the canopy shows the $\mathrm{BF}_{\text {exp }}$ phenotype from then on. This change in $\mathrm{BF}_{\mathrm{pot}}$ takes place between seasonal growth cycles and appears to occur in June.

Fenton MODELS. The application of the Fenton models shows that 'Carmel' is composed of a variable population of individual trees. Trees varied in their initial $\mathrm{BF}_{\mathrm{pot}}$ and thereafter underwent dynamic changes in $\mathrm{BF}_{\text {exp }}$ in relation to tree age, site location, and nursery practice. Each of the 12 nursery sources represented a separate and dynamic population that differed in the scion generation (clonal age) from which the source was collected and in $\mathrm{BF}_{\mathrm{pot}}$.

Somaclonal Change. Annual increases in $\mathrm{BF}_{\mathrm{exp}}$ occurred in 6 of the 7 years evaluated with essentially no change occurring in 1996. The rate of $\mathrm{BF}_{\text {exp }}$ increase was not constant over years. Different clonal sources

Fig. 6. Regression of the previous June average daytime temperatures to the subsequent annual increase in percent bud failure (BF) observed from 1991 to 1998 .

BF change and temperatures $(P=0.05)$ occurred for the month of June (Fig. 5). The highest correlation was obtained with the average daytime temperature (0600 to $1800 \mathrm{HR}$ ) followed by the 24-h average temperature and DD 15 to $32^{\circ} \mathrm{C}$. The regression of the previous June average daytime temperatures to the subsequent increase in percent BF is shown in Fig. 6.

\section{Discussion}

The present study provides a comprehensive analysis of the variability in $\mathrm{BF}$ within populations of 'Carmel' trees originating from 12 different nursery sources and grown in the same location maintained synchrony for $\mathrm{BF}_{\text {exp }}$ (Fig. 4), suggesting that some environmental parameter affected the yearly rate of change for all progeny. Previously, the rate of increase in $\mathrm{BF}_{\text {exp }}$ had been shown to be related to the accumulated annual exposure to total summer heat (Kester and Asay, 1978a), as measured by DD $>28$ ${ }^{\circ} \mathrm{C}$ (Fenton et al., 1988a). By relating the annual percent increase in $\mathrm{BF}_{\text {exp }}$ with various monthly parameters of temperature, the present experiment found a highly significant correlation between average daytime June temperatures and the increase in the average $\mathrm{BF}_{\text {exp }}$ during the subsequent growing season (Fig. 5). DD 15 to $32^{\circ} \mathrm{C}$ (i.e., expressing a growth optimum) also showed a high correlation whereas DD $>28^{\circ} \mathrm{C}$ (i.e., representing heat stress) showed lower but still positive correlations.

Results demonstrate the value of expression models for characterizing the incidence of this type of genetic-disorder. These 
models also offer powerful tools for controlling BF and similarly inherited genetic disorders through appropriate source budwood selection.

\section{Literature Cited}

Almond Board of California. 2002. Almond almanac. Almond Board of Calif., Modesto. p. 25.

CDFA 1984. Deciduous Fruit and nut program regulations. http: //fpms.ucdavis.edu/Tree/CDFATree Regs.html.

DiTerlizzi, B., M. Digiaro, and V. Savino.1994. Preliminary studies on virus-like diseases in almond. Acta Hort. 373:293-308.

Fenton, C.A.L., D.E. Kester, and A.H. Kuniyuki. 1988a. Models for noninfectious bud-failure in almond. Phytopathology 78:139-143.

Fenton, C.A.L., A.H. Kuniyuki, and D.E. Kester, 1988d. Search for a viroid etiology for noninfectious bud-failure in almond. HortScience 23:1050-1052.

Hellali, R.L. and D.E. Kester. 1979. High temperature induced bud-failure symptoms in vegetative buds of almond plants in growth chambers. 104(3):375-378.

IPM Education and Publications. 2002. Integrated pest management for almonds. 2nd ed. Div. Agr. Nat. Res. Publ. 3308. Calif.Statewide IPM Project, Davis.

Kester, D.E. 1974. Noninfectious bud-failure in almond, p. 278-283. In: Virus diseases and disorders of stone fruits in North America. USDA Hndbk. 437.

Kester, D.E. 1968a. Noninfectious bud-failure, a nontransmissable inherited disorder in almond. I. Pattern of phenotypic inheritance. Proc. Amer. Soc. Hort. Sci. 92:7-15.

Kester, D.E. 1968b. Noninfectious bud-failure, a nontransmissable inherited disorder in almond II. Progeny tests for bud-failure. Proc. Amer. Soc. Hort. Sci. 92:16-28.

Kester, D.E. 1978. Comparative inheritance of noninfectious bud-failure $(\mathrm{BF})$ in almond $\mathrm{x}$ almond and almond $\mathrm{x}$ peach progenies. HortScience 13:372 (abstr.).

Kester, D.E. 1994. Solving the problem of noninfectious bud-failure in
California almond orchards. $1^{\text {St }}$ Intl. Symp. Almonds and Pistachio. Agrigento, Italy. Acta Hort. 373:35-40.

Kester Dale E, and R. N. Asay. 1978a. Variability in noninfectious budfailure of 'Nonpareil' almond. I Location and environment. J. Amer. Soc. Hort. Sci. 103:377-382.

Kester, D.E. and R.N. Asay. 1978b. Variability in noninfectious budfailure of 'Nonpareil'. II. Propagation source. Proc. Amer. Soc. Hort. Sci. 103:429-432.

Kester D.E. and T.M. Gradziel. 1996. Genetic disorders, p. 76-87. In: W.C. Micke (ed.). Almond production manual. Univ. Calif. Div. Agr. Nat. Resour. Publ. 3364.

Kester, D.E. and T.M. Gradziel, 1996. Almonds. In: J. Janick and J.M. Moore (eds.). Fruit breeding. vol. 3. Nuts. Wiley and Sons, New York.

Kester, D.E. and T.M. Gradziel. 2002. Genetic inheritance of $\mathrm{BF}_{\exp }$ in almond-Peach hybrid populations. Acta Hort. 591:249-252

Kester, D.E. and R.W. Jones. 1970. Noninfectious bud-failure from breeding programs of almond (Prunus amygdalus Batsch). J. Amer. Soc. Hort. Sci. 74:214-219

Kester, D.E., R. Hellali, and R. N. Asay.1976. Temperature sensitivity of a "Genetic Disorder" in clonally propagated cultivars of almond. HortScience 11(1):5-57.

Kester, D.E., K. Pelletreau, D. Durzan, and K.M. Shackel. 1990. Phenotypic expression of noninfectious bud-failure in Nonpareil almond. Intl. Hort. Congr. 1990. (abstr.).

Lawless, J.F. 1982. Statistical models and methods for lifetime data. John Wiley \& Sons. New York.

Lee, E.T. 1980. Statistical Models for survival data analysis. Lifetime Learning Publ., Belmont, Calif.

SAS Institute. 1998. SAS/Windows, V8. SAS Inst., Cary, N.C.

Weibull, W. 1951.A statistical distribution function of wide applicability. J. Appl. Mech. 18:293-297.

Wilson, E.E. and R.D. Schein. 1956, The nature and development of noninfectious bud-failure in almond. Hilgardia 24:519-542.

Woods, M.N. 1939. Two new varieties of: The Jordanolo and the Harpareil. USDA Circ. 542:1-12. 